patients who withdraw early are more likely to have frequent exacerbations. However, they insinuate that the negative binomial method accounts for this fact. This is incorrect: the negative binomial approach only analyses the data available in the study and does not extrapolate or impute the uncollected missing data on exacerbations after patients discontinue the study drug. Exacerbation rates after discontinuation of study drug are much higher, which can introduce bias [3, 4]. The magnitude of this bias is illustrated by the ICS trials on mortality, where the trials with incomplete follow-up found a significant $(p=0.04) 27 \%$ reduction in mortality with ICS compared with placebo [5,6], while the TORCH (Towards a Revolution in COPD Health) trial with complete follow-up and, thus, a proper intent-to-treat analysis, found a nonsignificant $(p=0.53) 6 \%$ increase in mortality with fluticasone alone compared with placebo [7]. Differences were also shown for exacerbations [8].

Secondly, the TRISTAN and ISOLDE trials imposed the discontinuation of ICSs prior to randomisation, which may affect the exacerbation rates. The mixture of patients who discontinue ICS with patients who initiate ICS or placebo will produce a convoluted effect of ICS [4]. Such analyses should thus be stratified by prior use of ICS.

Finally, the negative binomial distribution depends not only on a Poisson distribution for exacerbations in each patient, but also on a gamma distribution for the exacerbations between patients. In all examples, this second assumption appears to lead to higher estimates of exacerbation rates, lower estimates of rate ratios and lower $\mathrm{p}$-values. Such comparative analyses of the Optimal trial data report wide differences between methods, even after accounting for patient variability, such as p-values of 0.21 versus 0.06 [8]. Further statistical work will be needed to verify the validity of these assumptions.

In all, while refinements in the statistical analysis of exacerbations are important, they become futile if the trials are not properly designed. The TRISTAN and ISOLDE trials had two major design flaws that violate fundamental principles of randomised trial methodology and that cannot simply be corrected with data analysis. Therefore, it is inappropriate to draw any conclusions regarding the effectiveness of inhaled corticosteroids on chronic obstructive pulmonary disease exacerbations from these reanalyses.

\section{S. Suissa}

Division of Clinical Epidemiology, Jewish General Hospital, McGill University Health Centre, and the Depts of Epidemiology, Biostatistics and Medicine, McGill University, Montreal, Canada.

\section{STATEMENT OF INTEREST}

A statement of interest for $S$. Suissa can be found at www.erj.ersjournals.com/misc/statements.shtml

\section{REFERENCES}

1 Keene ON, Calverley PMA, Jones PW, Vestbo J, Anderson JA. Statistical analysis of exacerbation rates in COPD: TRISTAN and ISOLDE revisited. Eur Respir J 2008; 32: 17-24.

2 Suissa S. Statistical treatment of exacerbations in therapeutic trials of chronic obstructive pulmonary disease. Am J Respir Crit Care Med 2006; 173: 842-846.

3 Kesten S, Plautz M, Piquette CA, Habib MP, Niewoehner DE. Premature discontinuation of patients: a potential bias in COPD clinical trials. Eur Respir J 2007; 30: 898-906.

4 Suissa S, Ernst P, Vandemheen KL, Aaron SD. Methodological issues in therapeutic trials of COPD. Eur Respir J 2008; 31: 927-933.

5 Sin DD, Wu L, Anderson JA, et al. Inhaled corticosteroids and mortality in chronic obstructive pulmonary disease. Thorax 2005; 60: 992-997.

6 Ernst P, Suissa S. Inhaled corticosteroids and mortality in COPD. Thorax 2006; 61: 735.

7 Calverley PM, Anderson JA, Celli B, et al. Salmeterol and fluticasone propionate and survival in chronic obstructive pulmonary disease. $N$ Engl J Med 2007; 356: 775-789.

8 Aaron SD, Fergusson D, Marks GB, et al. Counting, analysing and reporting exacerbations of COPD in randomised controlled trials. Thorax 2008; 63: 122-128.

DOI: $10.1183 / 09031936.00108308$

\title{
Asymptomatic airway hyperresponsiveness: what does it mean?
}

\section{To the Editors:}

I read with interest the study by VAN DEN NIEUWENHOF et al. [1], which appeared in a recent issue of the European Respiratory Journal. The study's conclusion is certainly of interest: screening for asymptomatic airway hyperresponsiveness (AHR) in adolescents does not identify subjects at risk of developing asthma, whilst the presence of allergy is a risk factor for asthma. However, the observations leading to this statement should be interpreted with caution.
I agree with the authors that AHR may be variable. It can improve significantly at adolescence, the period associated with the highest incidence of asthma remission. The situation seems different in adults, however.

In some subjects, AHR may reflect a previous "insult" to the airways, either of infectious, toxic or allergic origin, or it could be the consequence of past airway inflammatory responses and associated structural changes, with persistence of the latter. In other subjects, however, AHR could reflect an ongoing 
inflammatory/remodelling process either from current environmental exposure or from a persistent activation of the immune system of undetermined origin.

In a previous study, my colleagues and I reported that atopic subjects with asymptomatic AHR and a family history of asthma, who were chronically exposed to indoor allergens to which they were sensitised (particularly domestic animals), were at higher risk of developing asthma in the near future [2]. Our study documented the changes occurring in the airways when subjects with asymptomatic AHR developed symptomatic asthma. These changes consisted mostly of an increase in airway remodelling and reversal of the CD4+/CD8+ lymphocyte ratio. Although the study included a limited number of subjects, these features were quite striking.

I had a chance to review this topic in recent years and my conclusions were that in some specific subgroups of patients, asymptomatic AHR is associated with an increased risk for the development of asthma [3]. More studies should be performed to define the population in which screening could be beneficial. Unfortunately, when symptomatic asthma develops, airway structural changes, which perhaps explain a large part of the physiological features observed, are largely irreversible and symptoms are persistent. The ideal would be to prevent this condition instead of simply trying to achieve optimal control once developed. In a recent editorial, P.J. Sterk and I suggested that we should try to prevent potentially detrimental airway structural changes, perhaps by controlling triggering mechanisms of the disease at an early stage or by adequately treating conditions associated with an increased risk of developing lower airways diseases (e.g. rhinitis) [4].

The risk of developing asthma is thought to be related to a combination of genetic and environmental factors. AHR per se may not be a predicting factor of asthma but when associated with atopy or a strong family history of asthma, it may indicate that a given subject is closer to the "asthmatic range" of airway responsiveness, and, as suggested in previous studies [2, 3], if exposed to a pro-inflammatory trigger, the subject may develop full-blown asthma in the coming months/years.

A study such as the one by VAN DEN NIEUWENHOF et al. [1] is welcome in terms of improving knowledge about the significance of airway hyperresponsiveness, but much remains to be determined if we are to more accurately identify those at risk of developing asthma in the near future and those who would benefit from early intervention for the prevention of asthma. The suggestion that screening for asymptomatic airway hyperresponsiveness cannot be generally recommended seems appropriate in the population studied but even then, it should not prevent investigation of the possibility that specific high-risk groups could be identified early and become candidates for preventative measures in order to try to avoid the development of symptomatic asthma. With regard to atopy as a risk factor of asthma, only a minority will develop asthma in the future and more emphasis should be placed upon finding ways to identify allergic subjects at high risk to develop asthma.

\section{L-P. Boulet}

Research Centre, Laval Hospital, Cardiology and Pneumology Institute of Laval University, Québec, QC, Canada.

\section{STATEMENT OF INTEREST}

A statement of interest for L-P. Boulet can be found at www.erj.ersjournals.com/misc/statements.shtml

\section{REFERENCES}

1 van den Nieuwenhof L, Schermer T, Heijdra Y, et al. Are asymptomatic airway hyperresponsiveness and allergy risk factors for asthma? A longitudinal study. Eur Respir J 2008; 32: 70-76.

2 Laprise C, Laviolette M, Boutet M, Boulet LP. Asymptomatic airway hyperresponsiveness: relationships with airway inflammation and remodelling. Eur Respir J 1999; 14: 63-73.

3 Boulet LP. Asymptomatic airway hyperrresponsiveness. A curiosity or an opportunity to prevent asthma? Am J Respir Crit Care Med 2003; 167: 371-378.

4 Boulet LP, Sterk PJ. Airway remodelling: the future. Eur Respir J 2007; 30: 831-834.

\section{The effect of inhaled lidocaine-hydrofluoroalkane 134a in prednisone-dependent eosinophilic bronchitis}

\section{To the Editors:}

We report on the preliminary findings with inhaled lidocaine in patients with eosinophilic airway inflammation, identified by sputum cell counts (eosinophilic bronchitis), with or without asthma, who are prednisone dependent. Lidocaine has been shown to possess anti-eosinophil [1,2] and anti-spasmodic [1, 3] actions, as well as steroid-sparing efficacy $[4,5]$. However, the anti-eosinophil effects have not been demonstrated in humans in vivo. Furthermore, the delivery of lidocaine by nebulisation, as utilised in previous clinical studies $[4,5]$, makes the treatment inconvenient. Therefore, we synthesised a preparation of lidocaine in a hydrofluoroalkane (HFA)134a, pressurised metered-dose inhaler (MDI) and investigated the prednisonesparing and anti-eosinophilic effects.

Five patients requiring daily prednisone in addition to highdose inhaled corticosteroid to treat eosinophilic bronchitis 